\title{
Resistance Training in People at Risk of Developing Type 2 Diabetes and Their Experience of Health-Related Quality of Life
}

\author{
Elisabeth Hansen ${ }^{*}$, Stig Vinberg1, Kjell Terje Gundersen², Bodil J. Landstad1,3 \\ ${ }^{1}$ Department of Health Sciences, Mid Sweden University, Östersund, Sweden \\ ${ }^{2}$ Faculty of Education, Nord University, Levanger, Norway \\ ${ }^{3}$ Levanger Hospital, Nord-Trøndelag Hospital Trust, Levanger, Norway \\ Email: *elisabeth.hansen@miun.se
}

How to cite this paper: Hansen, E., Vinberg, S., Gundersen, K.T. and Landstad, B.J. (2016) Resistance Training in People at Risk of Developing Type 2 Diabetes and Their Experience of Health-Related Quality of Life. Health, 8, 1323-1334.

http://dx.doi.org/10.4236/health.2016.813133

Received: August 18, 2016

Accepted: October 9, 2016

Published: October 12, 2016

Copyright $\odot 2016$ by authors and Scientific Research Publishing Inc. This work is licensed under the Creative Commons Attribution International License (CC BY 4.0).

http://creativecommons.org/licenses/by/4.0/

\begin{abstract}
Background: Research indicates an association between impaired glucose metabolism and overweight, a serious public health problem involving an increased risk of Type 2 diabetes, related hypertension, and a reduced quality of life. Aim: The first aim is to assess different dimensions of Health-Related Quality of Life (HRQoL) in overweight individuals at risk of developing Type 2 diabetes compared to a normal population. The second aim is to examine the impact of resistance training on the pre-post HRQoL dimension scores of the intervention group. Methods. Eighteen participants were randomly assigned to one of the two resistance training groups. Group 1 engaged in supervised maximal resistance training (Bernstein inverted pyramid system: $5 \times 3-4,60 \%-85 \%$ of 1 Repetition Maximum (RM)), three days/week over four months, and Group 2 performed endurance resistance training (including lower weight loads and more repetitions over four months). The intervention consisted of eight exercises involving the entire body. The subjects completed the Short-Form Health Survey (SF-36) on HRQoL. The HRQoL scores of the norm population were higher than those of people at risk of developing Type 2 diabetes, and resistance training seemed to have a limited significant positive effect on the different HRQoL dimensions.
\end{abstract}

\section{Keywords}

Resistance Training, IGT, Impaired Glucose Tolerance, HRQoL, Health-Related Quality of Life, Intervention Study 


\section{Introduction}

The World Health Organization (WHO) estimates that the prevalence of diabetes will more than double from 1997 to 2025 among adults, with an estimated increase from 143 million to 300 million cases. In 2000, the WHO reported a global prevalence of diabetes of 171 million people, and the expected prevalence in 2030 was predicted to be 366 million people [1] [2]. Physical inactivity and increased body weight are expected to increase the prevalence of Type 2 diabetes in Europe from 3.5\% to $4.75 \%$ in the next 25 years [3] [4]. Impaired glucose metabolism and overweight present a serious public health problem, leading to an increased risk of developing Type 2 diabetes, as well as related hypertension and reduced quality of life (HRQoL) [4] [5]. The challenges faced by those at risk of developing Type 2 diabetes can include a reduced capacity and thus a risk of becoming vulnerable to exclusion from working life, given the risk of developing a more serious illness in the future [6]. Physical functioning seems to decrease gradually across categories of glucose tolerance status [7]. Physical functioning might worsen when a person develops more severe diabetes symptoms [8]. People with an elevated risk of developing Type 2 diabetes in a population-based study in Finland [9] differed significantly on HRQoL for four of eight dimensions when compared with the reference values for the general population [10]. Two of the dimensions seemed worse (general health and bodily pain) than in the general population, while two other dimensions appeared to be better (mental health and emotional role limitations). Findings on subjective vitality are hypothesized to reflect organismic well-being [11] [12]. Those who

score lower on vitality include people who experience more chronic pain than their counterparts in control groups. Furthermore, vitality seems to be associated with selfmotivation and maintenance of weight loss in people treated for obesity (ibid). Physical activity is a key element to the prevention and management of Type 2 diabetes [13][15] and to improved HRQoL [16]. Earlier research showed few positive results between physical activity and quality of life, measured by feelings of increased happiness and subjective wellbeing [17]. Hakkinen and colleagues [10] demonstrated that regular physical activity positively influenced all dimensions of HRQoL. Resistance training is recognized as an intervention approach for the primary prevention of obesity and for reducing the risk of Type 2 diabetes [1] [13] [18]. Both maximal resistance training and endurance resistance training decrease insulin resistance, with maximal resistance training leading to increased glucose uptake and endurance resistance training to increased insulin sensitivity [19]. A review by Martinsen [20] addresses the lack of studies on dose-response effects of physical exercise on psychological changes. Tapp and colleagues [5] show that being newly diagnosed with Type 2 diabetes, or being at high risk of developing diabetes, is associated with reduced health-related functioning, independent of the presence or absence of diagnosed cardiovascular disease. Generally, aerobic physical activity contributes to larger capillary density and increased oxygen uptake, which positively supplies the regulation of glucose transport and uptake [21]. Skeletal muscles account for $70 \%-80 \%$ of the glucose uptake stimulated by insulin, and it has been proven that physical activity may increase the uptake of glucose stimulated by in- 
sulin in plasma (ibid.). The mechanisms involved include, for example, increased capillary concentrations of GLUT 4 (a glucose transporter) [22], a change towards increased insulin sensitivity in muscle fibers, possible changes in phospholipids in sarcolemma, increased glycolytic and oxidative enzyme activity in the muscles and enhanced glycogen synthesis [23]. The joint effect of these changes due to physical activity is a more effective vascular transport of glucose and improved glucose transport into cells as well as an improvement in metabolism. In light of these changes, it is possible that resistance training and the related hypertrophy could present an efficient primary as well as secondary method of prevention in the risk of developing Type 2 diabetes. Resistance training stimulates insulin sensitivity by improving glucose regulation. In addition, insulin influence stimulates and increases the uptake of glucose from the bloodstream into the muscle. The increase in muscle mass caused by resistance training may be an important contributor to this process [15] [23]. Research regarding the effects of resistance training on HRQoL among people at risk of developing Type 2 diabetes is sparse. The first aim of the study is therefore to compare national normative data from healthy Norwegians with data from individuals at risk of developing Type 2 diabetes (those with IGT) on eight HRQoL dimensions [24]-[26] (Vitality = VT, Social function $=$ SF, Emotional role limitation $=\mathrm{RE}$, Mental health $=\mathrm{MH}$, Physical functioning $=\mathrm{PF}$, Bodily pain $=\mathrm{BP}$, General health $=\mathrm{GH}$ and Physical role limitations $=\mathrm{RP}$ ). The second aim of the study is to assess the impact of resistance training interventions on these dimensions by comparing baseline values with intervention values.

\section{Methods}

To investigate HRQoL among pre-diabetics compared to a normative population and to study whether resistance training has any effect on HRQoL, several analyses including internal consistency between the (output) variables and a comparison of mean values and effect data were conducted.

\subsection{Subjects}

This study is based on data from the Second North-Tröndelag Health Survey (HUNT II) in which 2000 subjects were invited to be screened for diabetes or impaired glucose tolerance (IGT) [15]. Approximately 1100 subjects responded, and of these, 55 individuals were classified with diabetes and 94 individuals with IGT based on the WHO definition [27]. In the at-risk group of 94 individuals, 70 were eligible to participate in an intervention study, and 18 responded positively to participating in the present study [6]. These individuals were randomly assigned to one of two resistance training intervention groups $(\mathrm{N}=18,14$ female and 4 male participants, age 33 - 69). Participants in both groups ( 9 individuals, respectively) fulfilled the criterion for overweight according to body mass index (BMI) (Group 1: $\mathrm{M}=28.55, \mathrm{SD}=4.3$; Group 2: $\mathrm{M}=27.17, \mathrm{SD}=$ 4.1). All participants were classified as sedentary and had not engaged in regular physical activity for at least six months prior to the start of the study. Two men were randomized into each group. Although the study did not analyze possible gender differences 
due to the few men in the study, male participants were included to retain the total number of the population. During the intervention period, there were two drop-outs. The present study is part of a larger investigation on several significant parameters of this high-risk population, those with IGT, and the findings of the study might provide an additional interesting perspective on the issues focused on in this paper. More detailed information on the clinical measurements, blood samples and body composition are reported in an earlier study [19] [28].

\subsection{Intervention}

The interventions started with three weeks of instruction on the techniques of performing each exercise. The interventions were supervised individually and were strictly guided and followed by qualified personnel at the training center where the intervention took place. The participants were encouraged to avoid heavy exercise the day before exercising. They were further instructed to avoid alcohol, smoking, coffee, tea, heavy meals or large amounts of sugar 2 - 3 hours before exercising. The participants wore lightweight clothing and shoes that were suited to the exercise. Individual logs were used to record the time of day work-outs took place as well as general information on health conditions and weight loads for each exercise. The exercises were self-administered at the fitness center, with access to competent guidance from the center's management and instructors at any time. The programs engaged the entire body and were implemented in 2 - 3 workouts each week for 4 months at a fitness center. The intervention program consisted of eight exercises for the whole body and included the following: a) abdominal muscles (total abdominal); b) lower back; c) press for thighs; d) leg press; e) chest press; $\mathrm{f}$ ) arm press, extension for triceps; $\mathrm{g}$ ) pull down for upper back and $\mathrm{h}$ ) arm curl for biceps. Before the resistance exercises were performed, the person walked for 10 minutes on a treadmill to warm up. Resistance training was followed by another 10 minutes of walking on the treadmill to cool down.

The maximal resistance group ( $\mathrm{n}=9$, seven female and two male participants) followed a program with a high weight load and few repetitions based on the Bernstein inverted pyramid training model [29], with $60 \%-85 \%$ of 1 RM (3 - 4 repetitions) 3 days per week over a 4 -month period. To make the 3 - 4 repetitions manageable, the work load had to be slightly reduced for successive bouts of exercise because of the induced anaerobic conditions in the muscles being targeted. Each bout of exercise was followed immediately by a new bout without breaks in between, for a total of 5 bouts (approximately 20 repetitions) per set. The endurance resistance group ( $\mathrm{n}=9$, seven female and two male participants) followed a program with a lower weight load and more repetitions according to a standard procedure for endurance resistance training (ERT) at $45 \%-65 \%$ of 1 RM ( 3 bouts at 12 - 15 repetitions for approximately 45 repetitions). The break between training bouts lasted between 30 and 60 seconds. Additional information about the programs, randomization, standardization, procedures, content, workout intervals, and repetitions of exercises are reported in detail by Hansen and colleagues [15] [29]. 


\subsection{Questionnaires and Reliability Tests}

The subjects completed questionnaires administered by the project supervisor, which included items on all dimensions of the Short-Form Health Survey (SF-36) [24]-[26]. The SF-36 was grouped into eight multi-item scales including PF (10 items), RP (4 items), RE (3 items), BP (2 items), SF (2 items), MH (5 items), VT (4 items) and GH (5 items). The items included in HRQoL were aggregated to create summary indexes of 8 dimensions. The internal consistency coefficients of the 35 HRQoL items, with a total index CA (Cronbach's Alpha) $=0.91$, were high and justified the use and reliability of the instrument being valid. The Norwegian translation of the SF-36 and the dimensions of the scale have been tested and slightly refined to achieve satisfactory reliability and validity (ibid.). According to a standardized procedure (Medical Outcome Trust) [30], the raw scores for each item in the dimensions were coded, summed and translated into the eight dimensions of HRQoL, with scores from 0 - 100 ( 0 = lowest possible HRQoL, $100=$ highest possible HRQoL). In the present study, after investigating the eight dimensions individually, two of the dimensions (Social functioning and Emotional role limitation) were excluded from further analyses due to a low internal consistency. The six remaining dimensions (Physical functioning $\mathrm{CA}=0.81$, Physical role limitations $\mathrm{CA}$ $=0.96$, Bodily pain $\mathrm{CA}=0.91$, Mental health $\mathrm{CA}=0.71$, Vitality $\mathrm{CA}=0.87$ and General health $\mathrm{CA}=0.55)$ indicated moderate to very high internal consistency and thereby high reliability.

\section{Ethics}

Written informed consent was obtained from each study participant in accordance with the Helsinki Declaration [31]. The study was approved by the Regional Committee for Ethics in Medical Research (Ref. No. 4.2006.2549).

\subsection{Statistical Analyses}

Analyses involved the use of SPSS 21.0 software (SPSS Inc, Chicago, Ill, USA) with descriptive statistics, internal consistency CA, means, standard deviation (SD) and paired sample t-tests. The effect data mean SF-36 scale scores and SD, calculated for the six included dimensions of the SF-36 by T-tests and comparison of means, revealed no significant effect differences on any of the dimensions between the two resistance groups. Thus, the two groups were merged into one resistance intervention training group. Subsequently, the total number of participants was satisfactory $(\mathrm{N}=16)$ for further analysis. Then, a simple comparison of data was performed including the mean SF-36 scale scores and SD for people at risk of developing Type 2 diabetes compared to normative data from the general Norwegian population. Finally, a simple paired t-test was carried out to compare the mean values and SD of the SF-36 in the intervention study population, those at risk of developing Type 2 diabetes, pre- and post-intervention.

\section{Results}

The characteristics of the intervention group are briefly described in Table 1 . The 
Table 1. Descriptive data of the study group $(\mathrm{N}=18)$.

\begin{tabular}{lc}
\hline Gender $(\mathrm{N}=18)$ & \\
Men & 4 \\
Women & 14 \\
Age (Mean Age) & 54.0 \\
Men & 45.5 \\
Women & \\
Civil status $(\mathrm{N}=18)$ & 3 \\
Single/widow & 15 \\
Married/cohabited & \\
Occupational position $(\mathrm{N}=18)$ & 15 \\
Employed & 3 \\
Unemployed & \\
Education level (N = 18) & \\
Lower secondary school & 5 \\
Higher secondary school & 11 \\
University (3 years or more) & 2
\end{tabular}

group is predominantly female, and most of the participants are married/cohabited and employed.

The present study population, people at risk of developing Type 2 diabetes, had different outcomes on the SF-36 scale than the normal population. The mean scores for each of the six dimensions included in the study are mainly lower for the group at risk of developing Type 2 diabetes compared to the general Norwegian population, with the exception of Mental Health and Vitality (Table 2). Higher scores on the mean values in the table indicate better health. Concerning the HRQoL dimensions of physical functioning, role limitations, bodily pain and general health perceptions, the values of the study group are clearly lower than those of the normative population group consisting of both males and females. Concerning the mental health and vitality dimensions, the values are nearly the same for both groups. These results indicate and confirm the poorer HRQoL among people at risk of developing Type 2 diabetes compared to the general Norwegian population.

When comparing the pre- and post-test values for before and after the resistance training intervention, the analyses show that Bodily pain had an almost significant ( $\mathrm{p}=$ 0.057 ) effect on the difference of means (Table 3 ). The pre-intervention value (mean = 62.4 ) and the post-intervention value (mean $=75.9)$ show a positive development in the intervention group. Regarding the dimensions of physical functioning, role limitations, mental health, vitality and general health perceptions, the scores pre- and post-intervention are unchanged and non-significant.

\section{Discussion}

A comparison of normative data on healthy Norwegians and the data derived from the present study from individuals engaged in physical resistance training shows that the scores of healthy Norwegians are higher for four out of six dimensions of HRQoL, with the exception of the dimensions of Vitality and Mental health. As for Vitality and Men- 
Table 2. Mean Sf-36 scale scores (SD) for people at risk of developing Type 2 diabetes compared to normative data from the general Norwegian population (higher scores indicate better health).

\begin{tabular}{ccccccc}
\hline \multicolumn{3}{c}{ Normative data (Age range $\leq 29-\geq 70)$} & \multicolumn{2}{c}{ Present population (Age $\leq 33-\geq 69)$} \\
\hline \multicolumn{2}{c}{ Male $(\mathrm{N}=8775)$} & \multicolumn{2}{c}{ Female $(\mathrm{N}=9155)$} & \multicolumn{2}{c}{ Pre $(\mathrm{N}=18)$} \\
\hline MF & 89.8 & $(15.5)$ & 84.8 & $(20.8)$ & 41.35 & $(8.79)$ \\
RP & 80.5 & $(33.6)$ & 75.4 & $(37.7)$ & 56.25 & $(19.89)$ \\
BP & 77.2 & $(25.0)$ & 73.0 & $(26.6)$ & 62.50 & $(18.26)$ \\
MH & 80.0 & $(15.8)$ & 77.6 & $(17.0)$ & 76.83 & $(8.23)$ \\
VT & 63.2 & $(19.9)$ & 56.9 & $(21.2)$ & 58.33 & $(16.99)$ \\
GH & 77.4 & $(21.3)$ & 76.3 & $(22.5)$ & 66.05 & $(14.64)$ \\
\hline
\end{tabular}

$\mathrm{PF}=$ physical functioning; $\mathrm{RP}=$ role limitations, physical; $\mathrm{BP}=$ bodily pain; $\mathrm{MH}=$ mental health; $\mathrm{VT}=$ vitality; $\mathrm{GH}$ = general health perceptions.Normative data from the general Norwegian population (Loge \& Kaasa, SJPH 1998).

Table 3. Mean Sf-36 scale scores (SD) for people at risk of developing Type 2 diabetes Pre intervention/training population compared to Post intervention/training (higher scores indicate better health). $\mathrm{N}=16$.

\begin{tabular}{|c|c|c|c|c|c|c|}
\hline & \multicolumn{6}{|c|}{ Present population (Age range $\leq 33-\geq 69$ ) } \\
\hline & \multicolumn{2}{|c|}{ Pre intervention } & \multicolumn{2}{|c|}{ Post intervention } & \multirow[b]{2}{*}{$\mathrm{t}$} & \multirow[b]{2}{*}{$\mathrm{p}$} \\
\hline & Mean & SD & Mean & SD & & \\
\hline $\mathrm{PF}$ & 40.58 & $(9.00)$ & 42.89 & $(6.67)$ & -0.777 & 0.449 \\
\hline $\mathrm{RP}$ & 53.91 & (19.88) & 54.30 & $(17.49)$ & -0.057 & 0.955 \\
\hline $\mathrm{BP}$ & 62.41 & (19.44) & 75.91 & $(17.31)$ & -2.060 & 0.057 \\
\hline $\mathrm{MH}$ & 77.37 & $(7.29)$ & 74.25 & $(12.38)$ & 0.840 & 0.414 \\
\hline $\mathrm{VT}$ & 59.38 & $(17.65)$ & 62.24 & $(16.30)$ & -0.435 & 0.670 \\
\hline $\mathrm{GH}$ & 66.49 & $(15.50)$ & 73.26 & $(11.68)$ & -1.570 & 0.137 \\
\hline
\end{tabular}

$\mathrm{PF}=$ physical functioning; $\mathrm{RP}$ = role limitations, physical; $\mathrm{BP}=$ bodily pain; $\mathrm{MH}=$ mental health; $\mathrm{VT}$ = vitality; $\mathrm{GH}$ $=$ general health perceptions.

tal health, the scores of individuals in this study are slightly below or almost even with those of the normative comparison group of Norwegians. Some studies concerning the SF-36 dimensions of HRQoL have investigated individuals with Type 2 diabetes and individuals at risk of developing Type 2 diabetes (those with IGT). Tapp and colleagues [5] found that IGT and new diagnoses of Type 2 diabetes were associated with increased BP. Additionally, those with incident IGT and diagnosed Type 2 diabetes had significantly reduced physical functioning, GH, MH and VT compared with those with a normal glucose tolerance. These findings are somewhat in accordance with the present study. Kamarul and colleagues [32] concluded that Type 2 diabetes patients with poor glycemic control had lower mean SF-36 scores for Physical health, General health, Social function and Mental health compared to a group with better glycemic control. The scores of patients with Type 2 diabetes were also lower than the norm 
scores for the Malaysian population. The present study provides similar results for the same dimensions, except for Mental health. Other studies support or do not support these results, and some even contradict these conclusions. Häkkinen and colleagues [10] concluded that physically active individuals with an elevated risk of Type 2 diabetes had reduced HRQoL in the General health and Bodily pain dimensions. However, compared with the Finnish general population [9], Mental health and Emotional role limitations were better, which contradicts the present results. The low scores among subjects at risk of developing Type 2 diabetes on almost all dimensions of the SF-36 cannot be explained empirically in the present study. However, Hansen and colleagues [15] [28] argue for the possibility that negative influences are caused by previous screening tests and accompanying information about health complaints linked to Type 2 diabetes. These may have aroused serious concerns in individuals at risk of Type 2 diabetes about their future health status, which may have been reflected in the present investigation in the questionnaires. Unexpectedly, diabetics are generally less concerned about their health status than individuals with IGT [28] [33] [34]. Some of the affected patients believe that Type 2 is a milder form of diabetes, not to be taken seriously, and this might positively affect their state of mind. They are often aware of the health problems associated with diabetes and the possibility of comorbidity, exemplified by the risk of developing cardiovascular disease and cerebral infarction. Furthermore, the standard procedure when delivering a medical diagnosis is to inform the patient about potential complications and to refer them to rehabilitation programs, including those directed at developing a healthier lifestyle [1]. Consequently, a number of patients choose to alter their behavior [15] [33]. This may create the perception that they are at a lower risk of developing more serious diseases. The present study is one of only a few to reveal any effects of resistance training on HRQoL dimensions among those with IGT. The nonsignificant SF-36 effect scores, except for the near significance of Bodily pain, may be due in part to the relatively small number of subjects. However, the fact that Bodily pain seems to be reduced after resistance training is of importance and might be explained by hormone release; for instance, a higher level of adrenaline might reduce the feeling of pain during or after resistance training. This finding may even be a reflection of a positive stressor effect due to environmental influence. According to Rosmond [35], environmental stress and the hypothalamic-pituitary system levels of circulating cortisol may be related. Additionally, the sensation of less stress may reduce the levels of cortisol, which in turn causes less pain. The suggested link between stress and pain in the present study is unclear and should be further explored in a larger study with a larger number of participants. This study and previous ones [5] found that Physical functioning seems to decrease gradually across categories of glucose tolerance status, which is an important finding for future health prevention and promotion programs targeting those at high risk of developing diabetes and other serious metabolic illness. Compliance to a physical training program may fail due to a lack of motivational resources needed to cope with the demands of exercise. Personality as well as mood differences may reflect individual differences that relate to the underlying differences in 
motivation and coping resources [1]. Predisposing personality factors reside within the individual more than they reflect work environment and family life, and they may also be of importance in changing unhealthy lifestyles. Personality may influence the appraisal of perceived stress and the attribution of coping resources as well as mood changes induced by physical activity [15]. Individual differences in psychological characteristics are therefore potential predictors and consequences of the effects of exercise programs.

\section{Conclusion}

The results of our study clearly indicate a lower HRQoL among the study population in comparison to the normative population sample. By comparing the dimension scores before and after the resistance intervention, bodily pain was found to improve. The findings from the present study when viewed in light of other research indicate the importance of the associations of aspects of HRQoL with impaired glucose metabolism and resistance training. Health promotion and efforts to prevent disease are based on an understanding of the process of declining health prior to an illness. People at risk of Type 2 diabetes, who are often overweight and sometimes inactive, already have reduced capacity [6] [15]. Resistance training may have an impact on bodily pain, supporting the recommendation of using exercise with resistance training as an intervention approach for individuals at risk of developing Type 2 diabetes to promote their HRQoL. Further studies with larger populations and large-scale intervention are needed to confirm these suggestions.

\section{Limitations of the Study}

The study includes a small number of participants, and the results must therefore be interpreted with caution. The non-significant HRQoL dimension scores might be explained by the small sample size. Larger populations may increase the external validity of the findings. However, it is important to study this specific group at risk of developing IGT and more serious lifestyle-related illnesses. The study is not generalizable, but it might provide a contribution to this research field. It is notable that the scores on the quality of health dimensions are lower in this study compared to the normative data, which points to the importance of general public health measures for individuals at risk of developing Type 2 diabetes.

\section{Acknowledgements}

The participants are acknowledged for their willingness to take part in the project.

\section{Conflict of Interest}

There are no conflicts of interest among the authors. This project was supported by grants from the EU-program Interreg III A, Nord-Trøndelag University College, Norway, and Mid Sweden University. 


\section{References}

[1] Hansen, E., Landstad, B.J., Hellzen, O. and Svebak, S. (2011) Motivation for Lifestyle Changes to Improve Health in People with Impaired Glucose Tolerance. Scandinavian Journal of Caring Sciences, 25, 484-490. http://dx.doi.org/10.1111/j.1471-6712.2010.00853.x

[2] Bo, S., Ciccone, G. and Baldi, C. (2007) Effectiveness of a Lifestyle Intervention on Metabolic Syndrome. A Randomized Controlled Trial. Journal of General Internal Medicine, 22, 1695-1703. http://dx.doi.org/10.1007/s11606-007-0399-6

[3] Williams, G.C., Freedman, Z.R. and Deci, E.L. (1998) Supporting Autonomy to Motivate Patients with Diabetes for Glucose Control. Diabetes Care, 21, 1644-1651.

http://dx.doi.org/10.2337/diacare.21.10.1644

[4] Wild, S., Roglic, G., Green, A., Sicree, R. and King, H. (2004) Global Prevalence of Diabetes Estimates for the Year 2000 and Projections for 2030. Diabetes Care, 27, 1047-1053. http://dx.doi.org/10.2337/diacare.27.5.1047

[5] Tapp, R.J., O’Neil, A., Shaw, J.E., Zimmet, P.Z. and Oldenburg, B.F., Group AS (2010) Is There a Link between Components of Health-Related Functioning and Incident Impaired Glucose Metabolism and Type 2 Diabetes? The Australian Diabetes Obesity and Lifestyle (AusDiab) Study. Diabetes Care, 33, 757-762. http://dx.doi.org/10.2337/dc09-1107

[6] Hansen, E., Landstad, B.J., Gundersen, K.T. and Svebak, S. (2012) The Relative Importance of Aerobic Capacity, Physical Activity and Body Mass Index in Impaired Glucose Tolerance and Type 2 Diabetes. Society, Health \& Vulnerability, 3.

[7] Tapp, R.J., Dunstan, D.W. and Phillips, P. (2006) Association between Impaired Glucose Metabolism and Quality of Life: Results from the Australian Diabetes Obesity and Lifestyle Study. Diabetes Research and Clinical Practice, 74, 154-161. http://dx.doi.org/10.1016/j.diabres.2006.03.012

[8] Weyer, C., Tataranni, P.A., Bogardus, C. and Pratley, R.E. (2001) Insulin Resistance and Insulin Secretory Dysfunction Are Independent Predictors of Worsening of Glucose Tolerance during Each Stage of Type 2 Diabetes Development. Diabetes Care, 24, 89-94. http://dx.doi.org/10.2337/diacare.24.1.89

[9] Saaristo, T., Peltonen, M., Keinänen-Kiukaanniemi, S., Vanhala, M., Saltevo, J., Niskanen, L., Oksa, H., Korpi-Hyövälti, E. and Tuomilehto, J. (2007) National Type 2 Diabetes Prevention Program in Finland: FIN-D2D. International Journal of Circumpolar Health, 66, 101-112. http://dx.doi.org/10.3402/ijch.v66i2.18239

[10] Häkkinen, A., Kukka, A., Onatsu, T, Järvenpää, S., Heinonen, A., Kyröläinen, H., TomasCarus, P. and Kallinen, M. (2009) Health-Related Quality of Life and Physical Activity in Persons at High Risk for Type 2 Diabetes. Disability and Rehabilitation, 31, 799-805. http://dx.doi.org/10.1080/08916930802354930

[11] Chan, J.C., Malik, V., Jia, W., Kadowaki, T., Yajnik, C.S., Yoon, K.H. and Hu, F.B. (2009) Diabetes in Asia: Epidemiology, Risk Factors, and Pathophysiology. The Journal of the American Medical Association, 301, 2129-2140. http://dx.doi.org/10.1001/jama.2009.726

[12] Ryan, R.M. and Frederick, C. (1997) On Energy, Personality, and Health: Subjective Vitality as a Dynamic Reflection of Well-Being. Journal of Personality, 65, 529-565. http://dx.doi.org/10.1111/j.1467-6494.1997.tb00326.x

[13] Colberg, S.R., Sigal, R.J., Fernhall, B., Regensteiner, J.G., Blissmer, B.J., Rubin, R.R., ChasanTaber, L., Albright, A.L., Braun, B., the American College of Sports Medicine and the American Diabetes Association (2010) Exercise and Type 2 Diabetes the American College of Sports Medicine and the American Diabetes Association: Joint Position Statement. Diabetes Care, 33, e147-e167. 
[14] Yamaji, S., Shinichi, D., Watanabe, N. and Uchiyama, M. (2010) Slow Movement Resistance Training in Women. Health, 2, 1156-1162.

http://dx.doi.org/10.4236/health.2010.210169

[15] Hansen, E. (2012) The Significance of Resistance Training and Psychobiology in Primary Prevention of Type 2 Diabetes among People with Impaired Glucose Tolerance. PhD Thesis, Faculty of Medicine, Department of Neuroscience, Norwegian University of Science and Technology, Trondheim.

[16] Harding, J., Freak-Poli, R.L., Backholer, K. and Peeters, A. (2013) Change in Health-Related Quality of Life amongst Participants in a 4-Month Pedometer-Based Workplace Health Program. Journal of Physical Activity and Health, 10, 533-543. http://dx.doi.org/10.1123/jpah.10.4.533

[17] Thrane, C. (1999) Fysisk aktivitet, helse og subjektivt velväre. Tidsskrift for Samfunnsforskning, 3, 283-309.

[18] Gram, B., Holtermann, A., Sögaard, K. and Sjögaard, G. (2012) Effect of Individualized Worksite Exercise Training on Aerobic Capacity and Muscle Strength among Construction Workers-A Randomized Controlled Intervention Study. Scandinavian Journal of Work, Environment \& Health, 38, 467-475. http://dx.doi.org/10.5271/sjweh.3260

[19] Hansen, E., Landstad, B.J., Gundersen, K.T., Torjesen, P.A. and Svebak, S. (2012) Insulin Sensitivity after Maximal and Endurance Resistance Training. Journal of Strength and Conditioning Research, 26, 327-334. http://dx.doi.org/10.1519/JSC.0b013e318220e70f

[20] Martinsen, E.W. (2008) Physical Activity in the Prevention and Treatment of Anxiety and Depression. Nordic Journal of Psychiatry, 62, 25-29. http://dx.doi.org/10.1080/08039480802315640

[21] Dela, F., Mikines, K.J. and Galbo, H. (1999) Physical Activity and Insulin Resistance in Man. In: Gerald, M., Reaven, M.D. and Ami Laws, M.D., Eds., Insulin Resistance: The Metabolic Syndrome $X$, Springer, Berlin, 97-120. http://dx.doi.org/10.1007/978-1-59259-716-1_6

[22] Zorzano, A., Palacín, M. and Gumà, A. (2005) Mechanisms Regulating GLUT4 Glucose Transporter Expression and Glucose Transport in Skeletal Muscle. Acta Physiologica, 183, 43-58. http://dx.doi.org/10.1111/j.1365-201X.2004.01380.x

[23] Ivy, J.L., Zderic, T.W. and Fogt, D.L. (1999) 1 Prevention and Treatment of Non-InsulinDependent Diabetes Mellitus. Exercise and Sport Sciences Reviews, 27, 1-36. http://dx.doi.org/10.1249/00003677-199900270-00003

[24] Loge, J.H. and Kaasa, S. (1998) Short Form 36 (SF-36) Health Survey: Normative Data from the General Norwegian Population. Scandinavian Journal of Public Health, 26, 250-258. http://dx.doi.org/10.1177/14034948980260040401

[25] Ware, J.E. and Gandek, B. (1998) Overview of the SF-36 Health Survey and the International Quality of Life Assessment (IQOLA) Project. Journal of Clinical Epidemiology, 51, 903-912. http://dx.doi.org/10.1016/S0895-4356(98)00081-X

[26] Ware Jr., J.E. and Sherbourne, C.D. (1992) The MOS 36-Item Short-Form Health Survey (SF-36): I. Conceptual Framework and Item Selection. Medical Care, 30, 473-483. http://dx.doi.org/10.1097/00005650-199206000-00002

[27] WHO Consultation (1999) Definition, Diagnosis and Classification of Diabetes Mellitus and Its Complications. Part 1, World Health Organization.

[28] Hansen, E., Landstad, B.J., Brønn, R., Gundersen, K.T. and Svebak, S. (2011) Exercise-Induced Changes in Body Fat, Upper Leg Skeletal Muscle Area, BMI and Body Weight in Overweight People with Risk of Developing Type 2 Diabetes. Acta Kinesiologiae Universi- 
tatis Tartuensis, 17, 66-79. http://dx.doi.org/10.12697/akut.2011.17.05

[29] Bernstein, R.K. (2011) Dr. Bernstein's Diabetes Solution: The Complete Guide to Achieving Normal Blood Sugars. Little, Brown and Company, Boston.

[30] Medical Outcomes Trust (1994) SF-36 Health Survey. Scoring Manual for English Language Adaptations: Australia/New Zealand, Canada, United Kingdom.

[31] World Medical Association Declaration of Helsinki (2008) Ethical Principles for Medical Research Involving Human Subjects.

[32] Kamarul, I.M., Ismail, A.A., Naing, L. and Wan Mohamad, W.B. (2010) Type 2 Diabetes Mellitus Patients with Poor Glycaemic Control Have Lower Quality of Life Scores as Measured by the Short Form-36. Singapore Medical Journal, 51, 157-162.

[33] Cradock, S. (2004) Helping Patients to Improve Self Management of Diabetes. Heart, 90, iv36-iv38. http://dx.doi.org/10.1136/hrt.2004.037622

[34] Tringham, J., Skinner, C. and Arundel, F. (2003) Health Beliefs of Those with Screen Detected Diabetes Are Different to Those Diagnosed Conventionally. Diabetic Medicine, 20, 79.

[35] Rosmond, R. (2003) Stress Induced Disturbances of the HPA Axis: A Pathway to Type 2 Diabetes? Medical Science Monitor, 9, RA35-RA39.

Submit or recommend next manuscript to SCIRP and we will provide best service for you:

Accepting pre-submission inquiries through Email, Facebook, LinkedIn, Twitter, etc. A wide selection of journals (inclusive of 9 subjects, more than 200 journals)

Providing 24-hour high-quality service

User-friendly online submission system

Fair and swift peer-review system

Efficient typesetting and proofreading procedure

Display of the result of downloads and visits, as well as the number of cited articles

Maximum dissemination of your research work

Submit your manuscript at: http://papersubmission.scirp.org/

Or contact health@scirp.org 